\title{
EAl Endorsed Transactions

\section{A 2D numerical simulation of blade twist effect on the aerodynamic performance of an asymmetric blade vertical axis wind turbine in low wind speed}

\author{
Hussain Mahamed Sahed Mostafa Mazarbhuiya ${ }^{1, *}$, Agnimitra Biswas ${ }^{1}$ and Kaushal Kumar Sharma ${ }^{1}$ \\ ${ }^{1}$ Mechanical Engineering Department, National Institute of Technology, Silchar, Assam, India-788010
}

\section{Abstract}

\begin{abstract}
For urban areas, small-scale vertical axis wind turbine (VAWT) is a promising energy harvester due to its compact structure. However, VAWT's performance is inferior in low wind speed of urban environment. Selection of proper design and operational parameters can give a desirable power output under such condition. In this paper, effect of trailing edge blade twist on aerodynamic performance of an asymmetric blade H-Darrieus VAWT at a wind speed (6.0 m/s) is investigated using 2D numerical simulation. Important aerodynamic parameters considering blade twists have been analysed. Although blade twist has not increased power coefficient magnificently, the same is improved with blade twist of $1^{\circ}$. However, further increase of the latter reduces the turbine performance. A maximum power coefficient of 0.171 is obtained at tip speed ratio 2.4 for $1^{\circ}$ blade twist configuration. Hence, the present study shows that blade twist should be very low for low wind speed application of H-Darrieus VAWT.
\end{abstract}

Keywords: blade aerodynamics, blade twist, CFD, low wind speed, built environment.

Received on 22 November 2019, accepted on 20 January 2020, published on 30 January 2020

Copyright (C) 2020 Hussain Mahamed Sahed Mostafa Mazarbhuiya et al., licensed to EAI. This is an open access article distributed under the terms of the Creative Commons Attribution licence (http://creativecommons.org/licenses/by/3.0/), which permits unlimited use, distribution and reproduction in any medium so long as the original work is properly cited.

doi: 10.4108/eai.13-7-2018.162828

${ }^{*}$ Corresponding author. Email: mdhussain0309@ gmail.com

\section{Introduction}

Wind is an important renewable energy source whose effective utilization can fulfill the demand of rising energy needs. Small-scale vertical axis wind turbine (VAWT) is a promising energy harvester due to its various advantages compared to the horizontal axis windmill. They have experienced renewed importance from researchers and manufacturers for energy generation in the urban areas. However, there is an issue about its performance in the urban areas that have low wind speed. VAWT's performance can be improved by selection of proper design and operational perimeters. Modifications of the blade designs itself influence the performance of VAWTs. Different techniques have been used for boosting up the power coefficient $\left(\mathrm{C}_{\mathrm{p}}\right)$ of H-Darrieus VAWT; such as deforming blades at leading edge [1] and trailing edge [2,3], using gurney flap [4] and flapped airfoil . Blade twist is also identified as a means for improving the VAWT's performance. Gupta and Biswas [5] investigated the effect of twisted blade trailing edge using 2D steady-state CFD analysis and recommended twisted blade for self-starting of symmetric blade H-Darrieus rotor as the blade exhibited positive lift at zero incidence during startup. The effect of trailing edge twist angle on steady-state performance of the rotor was also evaluated. The optimal twist angle for higher torque coefficient was reported to be $30^{\circ}$. Biswas and Gupta [6] also investigated the unsteady low wind speed aerodynamics of a two bladed H-Darrieus rotor having $30^{\circ}$ twist at blade trailing edge. The blade-fluid interaction was studied in detail to analyze improved power performance of 
the rotor compared to without blade twist rotor. Beri et al. [7] investigated the self-starting property of symmetric NACA 0018 airfoil blade modified at its trailing edge. Trailing edge modification was done by creating a flexible portion of the airfoil, which was located at about $70 \%$ of the blade chord length. Two dimensional unsteady flow analysis revealed that modified airfoil blade profile had better selfstarting at low tip speed ratios (TSR) compared to prominent cambered airfoil NACA 2415. Sobhani et al. [8] used blades for VAWT having cavities instead of conventional blades. They observed a $25 \%$ increase in average efficiencies of the rotor with blade cavity. The combination of semicircular dimple and gurney flap was also used to investigate the turbine performance. Ismail and Vijayaraghavan used the combination of dimple and gurney flap and obtained maximum average tangential force for VAWT [9]. Due to capability of maximizing the tangential force its use (gurney flap) might be apparent at low tip speed range. Bianchini et al. [10] recommended gurney flap at inner side of airfoil which extracted better torque at downwind half of turbine revolution. A parametric observation was also carried out to select an optimized geometrical model for urban environment [11]. Roh et al.[12] also reported that variation of blade profile influence the turbine power. A three bladed $\mathrm{H}$-Darrieus turbine has better aerodynamic performance than other blade configurations [13].

Design and operational parameters impact the performance of H-Darrieus VAWT. Increasing the aerodynamic performance of VAWT with symmetrical and asymmetrical blade at low wind speed is a great challenge as faced by previous researchers. In this paper to design an effective H-Darrieus VAWT for low wind speed of urban location, a six-digit asymmetric airfoil, NACA $63-415$ is selected. Twist is made at the trailing edge of the airfoil blade. It is anticipated that twist at the trailing edge would accelerate the flow at the blade trailing edge, which is otherwise slow and on the verge of separation. And which might increase the aerodynamic performance of the blades and the turbine as a whole. In this regard, a two dimensional numerical simulation is done for performance optimization of the considered H-Darrieus VAWT with trailing edge blade twists.

\section{Numerical and geometrical modelling}

Numerical simulation of H-Darrieus VAWT using Fluent CFD software is performed using finite volume method to solve the unsteady Reynolds average Naiver Stoke (URANS) equation. A viscous model consisting of four equations is used to simulate the low wind speed flow across the turbine. The four equations transition SST model has capability to capture the underlying flow physics associated with VAWT and has a good agreement with experimental results [14-16]. In VAWT simulation a flow transition from laminar to turbulent is present and hence it is suitable to use transition SST model [17]. The four equation model is based on the coupling of SST-k $\omega$ transport equations with addition of another two transport equations. A semi implicit method for pressure linked equation (SIMPLE) algorithm is used to couple pressure-velocity terms of URANS equation. Standard pressure and second order momentum spatial discretization scheme is used. A first order implicit transient formulation scheme is imposed. A convergence criterion of $10^{-3}$ is imposed for continuity, velocity and turbulent properties. The time step size $(\Delta t)$ is calculated using Eq. (1).

$$
\Delta t=\frac{\pi}{\omega \times 180}
$$

where $\omega$ denotes angular velocity of H-Darrieus VAWT. The number of time step is 1800, which completes five complete rotation of the turbine. Maximum iteration per time steps is retained as 20 . The boundary conditions like velocity inlet, pressure outlet and symmetry to the sidewall boundaries are imposed on the computational model as shown in Fig. 1. This rectangular model consists of one stationary and one rotating domain. The radius of rotating domain is enlarged to double of the radius of the turbine. Distance between inlet boundary condition and the turbine center is 10r, and the whole length of the computational domain is 30r. Blades are created in such a way that aerodynamic moment center remains at $25 \%$ of chord length.

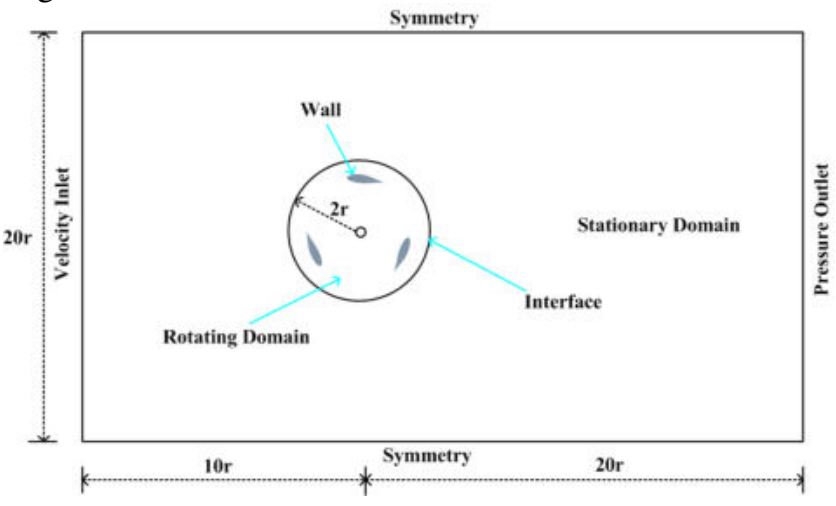

Figure 1. 2D H-Darrieus VAWT domain.

The detail geometrical description of the VAWT is given in Table 1.

Table 1. Details of the VAWT geometrical dimensions

\begin{tabular}{c|c}
\hline Blade profile & NACA 63-415 \\
\hline Number of blades $(\mathrm{N})$ & 3 \\
\hline Blade chord length (c) & $0.05 \mathrm{~m}$ \\
\hline Spoke-Blade connection & $25 \%$ of c \\
\hline Turbine diameter (D) & $0.5 \mathrm{~m}$ \\
\hline Turbine solidity $(\sigma)$ & 0.3 \\
\hline Wind speed $(\mathrm{U})$ & $6.0 \mathrm{~m} / \mathrm{s}$
\end{tabular}

The details of computational domain and mesh is shown in Fig. 2. The aerodynamic performance of NACA 63-415 is better [18] and hence it is selected for the turbine blade 
creation. A sliding mesh motion technique is used to compute the relative motion between rotating and stationary domain, which is recommended for time accurate solution [19]. These two domains are bounded by an interface. Different element size is used on computational domain (airfoil, rotating zone and stationary zone) to ensure the mesh quality and finalize the element size by grid independence test. An unstructured triangular mesh is used for the rotating and stationary domain whereas structural mesh is used near the airfoils periphery. A viscous sub-layer is generated on the airfoil boundary, which is resolved using inflation layers near the airfoil boundary. An inflation zone having 25 number of layers, $0.02 \mathrm{~mm}$ first layer thickness and growth rate of 1.1 is used. Governing equations namely continuity equation Eq. (2), x-momentum Eq. (3) and ymomentum Eq. (4) are solved to calculate the performance of the present turbine using ANSYS FLUENT CFD software.

$$
\begin{aligned}
& \nabla \cdot(\rho \vec{V})=0 \\
& \frac{\partial(\rho u)}{\partial t}+\nabla \cdot(\rho u \dot{V})=-\frac{\partial p}{\partial x}+\frac{\partial \tau_{x x}}{\partial x}+\frac{\partial \tau_{y x}}{\partial y} \\
& \frac{\partial(\rho v)}{\partial t}+\nabla \cdot(\rho v \dot{V})=-\frac{\partial p}{\partial y}+\frac{\partial \tau_{y y}}{\partial y}+\frac{\partial \tau_{x y}}{\partial x}
\end{aligned}
$$

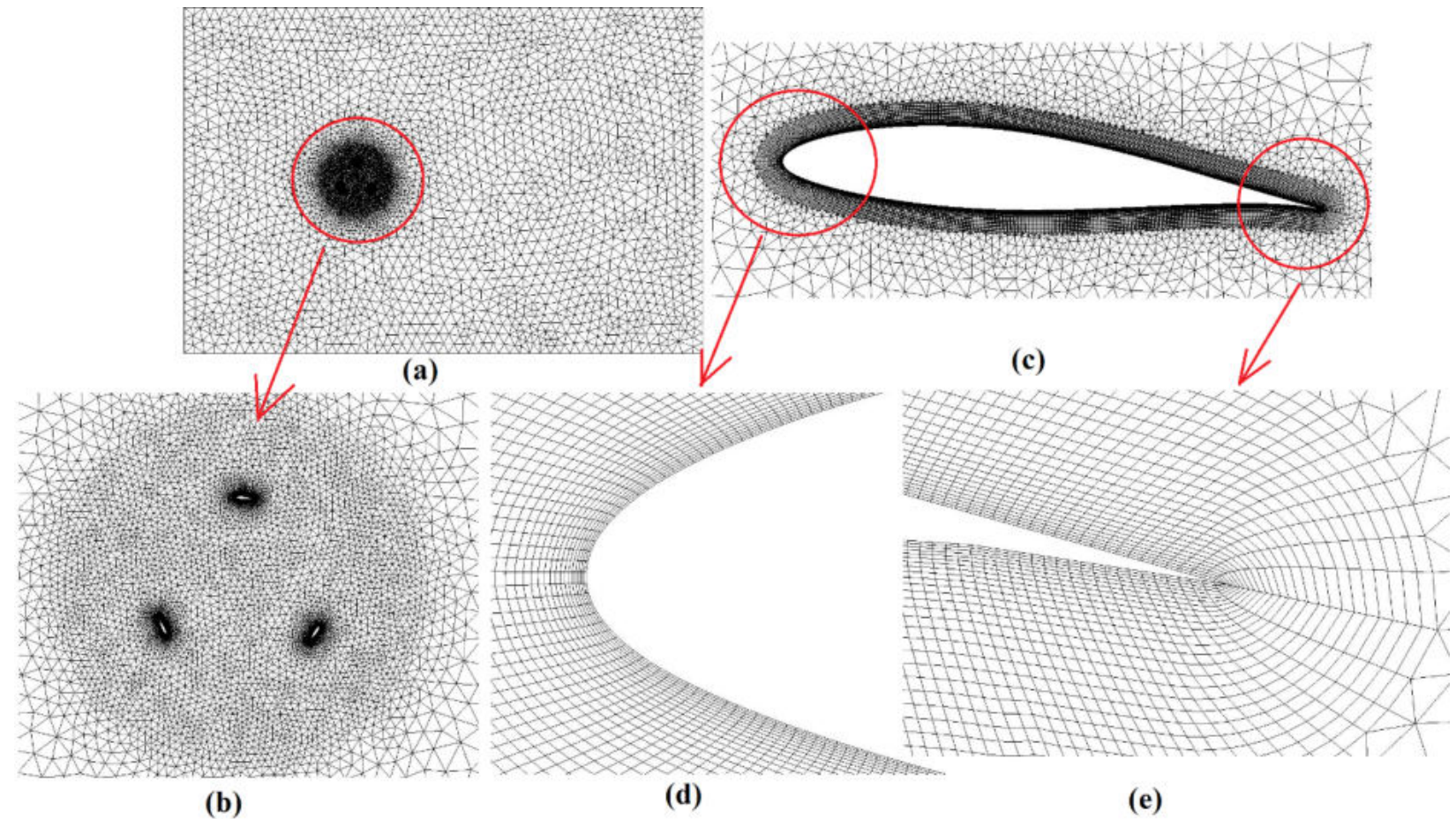

Figure 2. Computational domain and grid: (a) Domain and grid for VAWT, (b) grid near the rotating cell zone, (c) grid near the airfoil, (d) airfoil leading edge, (e) airfoil trailing edge.

\section{Sensitivity and validation}

For unsteady simulation study, it is necessary to identify the number of time steps, which is customarily classified in terms of turbine revolutions. Unnecessarily excess revolution of turbine in unsteady simulation consumes lots of memory from the computer system, which is a very time-consuming process and increase the project cost as well. In the present simulation of the considered wind turbine, five numbers of revolutions are considered. The relative change of $\mathrm{C}_{\mathrm{p}}$ with respect to the number of revolutions of the turbine is shown in Fig. 3. With starting of the turbine, the change of $\mathrm{C}_{\mathrm{p}}$ is maximum which is visible up to the $4^{\text {th }}$ revolution. A significant over estimation of turbine performance would be the reason during data sampling. A very little deflection $(0.06 \%)$ in
$\mathrm{C}_{\mathrm{p}}$ is obtained between the $4^{\text {th }}$ and $5^{\text {th }}$ turbine revolution. Similar trend of variation in $\mathrm{C}_{\mathrm{p}}$ is also reported by Rezaeiha et al. [20]. The angular velocity $(\omega)$ for the corresponding $\lambda$ is calculated using the Eq. 5 .

$$
\lambda=\frac{\omega D}{2 U}
$$

Table 2. Details of grids used in VAWT

\begin{tabular}{c|c}
\hline Grid size & No of elements \\
\hline Coarse & 22230 \\
\hline Medium & 130512 \\
\hline
\end{tabular}




$$
\begin{array}{l|r}
\text { Fine } & 233154
\end{array}
$$

The average $C_{p}$ of $5^{\text {th }}$ revolution of turbine is considered for further calculations. In order to ensure the quality of grid for VAWT, grid sensitivity analysis is conducted for three types of grids as described in Table 2 .

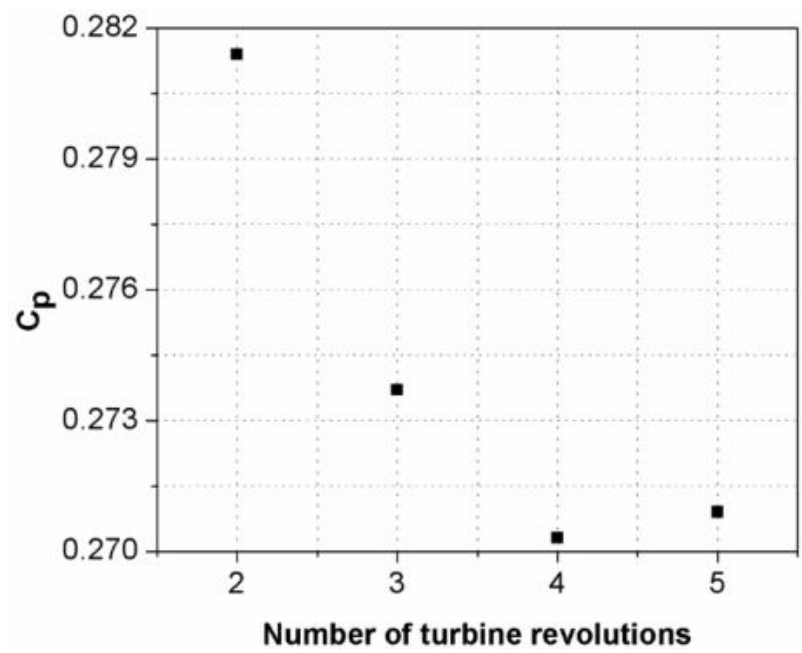

Figure 3. Relative change of $C_{p}$ with respect to turbine revolutions

The resolution of grids is systematically increased near the airfoils and the rotating zone. This process of grid sensitivity test is used widely in CFD studies. In this study, instantaneous moment coefficient $\left(\mathrm{C}_{\mathrm{m}}\right)$, lift coefficient $\left(\mathrm{C}_{\mathrm{l}}\right)$ and drag coefficient $\left(\mathrm{C}_{\mathrm{d}}\right)$ are monitored. The power coefficient $\left(\mathrm{C}_{\mathrm{p}}\right)$ of the turbine can be calculated using Eq. 6.

$$
C_{p}=C_{m} \times \lambda
$$

The variation of $\mathrm{C}_{\mathrm{m}}$ with azimuthal position for last revolution of turbine for a single blade is plotted in Fig. 4 for different grid sizes.

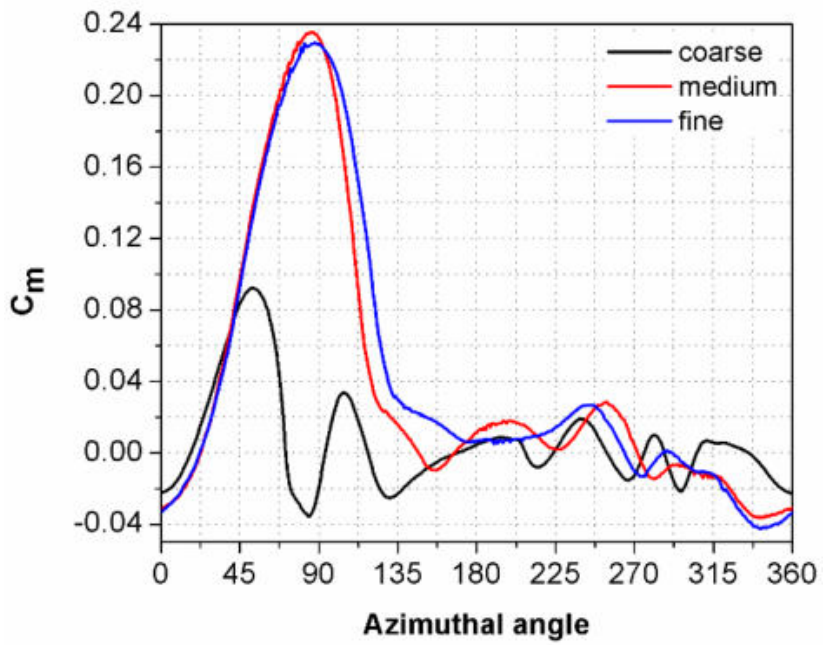

Figure 4. Variation of $\mathrm{C}_{\mathrm{m}}$ with azimuthal position for three grid resolution.

Due to increase in resolution of grids near airfoils boundary, there would be less overestimation of performance in viscous sub-layer zone of the airfoil and hence a notable increase in $\mathrm{C}_{\mathrm{m}}$ is recorded. The change in $\mathrm{C}_{\mathrm{m}}$ is negligible for further refinement in grid resolution from medium to fine. Based on this grid sensitivity test a medium grid is selected for further simulation. In order to investigate the sensitivity of different time step size, simulations are performed for azimuthal increments in the range $0.5^{\circ}$ to $2^{\circ}$. When the azimuthal increment is refined from $2^{\circ}$ to $1.5^{\circ}$, it results in $0.9 \%$ variation in $\mathrm{C}_{\mathrm{m}}$. Further refinement of azimuthal increment to $1^{\circ}$ and $0.5^{\circ}$ results in $0.5 \%$ and $0.3 \%$ variation in $\mathrm{C}_{\mathrm{m}}$, respectively. The change in $\mathrm{C}_{\mathrm{m}}$ with azimuthal position for different azimuthal increment is shown in Fig.5.

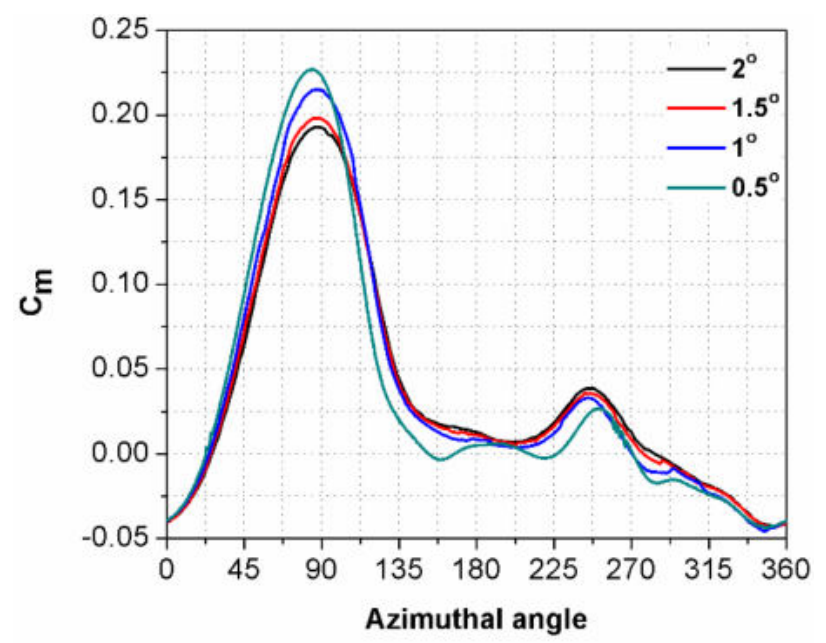

Figure 5. Variation of $\mathrm{C}_{m}$ with azimuthal angle for various azimuthal increment.

A major change in $\mathrm{C}_{\mathrm{m}}$ is observed towards upwind position. Although the peak $\mathrm{C}_{\mathrm{m}}$ is achieved at upwind position for $0.5^{\circ}$ azimuthal increment but the average $C_{m}$ is less due to negative $\mathrm{C}_{\mathrm{m}}$ achieved at $150^{\circ}$ and $220^{\circ}$ azimuthal position. From this investigation, it is observed that if azimuthal increment is reduced then simulation takes more time and computational memory. Hence, for present study an azimuthal increment of $1^{\circ}$ is preferred due to an economical computational time. Moreover, the variation in $\mathrm{C}_{\mathrm{m}}$ is very less $(0.3 \%)$ compared to $0.5^{\circ}$ azimuthal increment. In order to ensure the accuracy of numerical results, a validation study is performed. The $C_{p}$ value calculated from numerical simulation is compared with experimental results of Mazarbhuiya et al. [21] as shown in Fig. 6. The trend of the CFD results is matched with the experimental results. However, the overestimation in CFD results is due to neglecting the combined effect of the tip loss, struts' drag on the blades and due to the 2D simulation model, which is also reported in literature [22]. Also the maximum over- 
estimation in the present validation is less compared to the validation performed by previous researchers [19,22-24]. It is found from these literatures that the root mean square error (RMSE) are 25\%, 6.8\%, $7 \%$ and $8.5 \%$ in their validations, whereas in the present validation the RMSE is only $4.22 \%$, which is less compared to the published results of [19,22-24], and therefore it shows the accuracy of the present CFD results. The RMSE is obtained using Eq.7 [25].

$$
R M S E=\sqrt{\frac{\sum_{i=1}^{N}\left(\text { Predicted }_{i}-\text { Actual }_{i}\right)^{2}}{N}}
$$

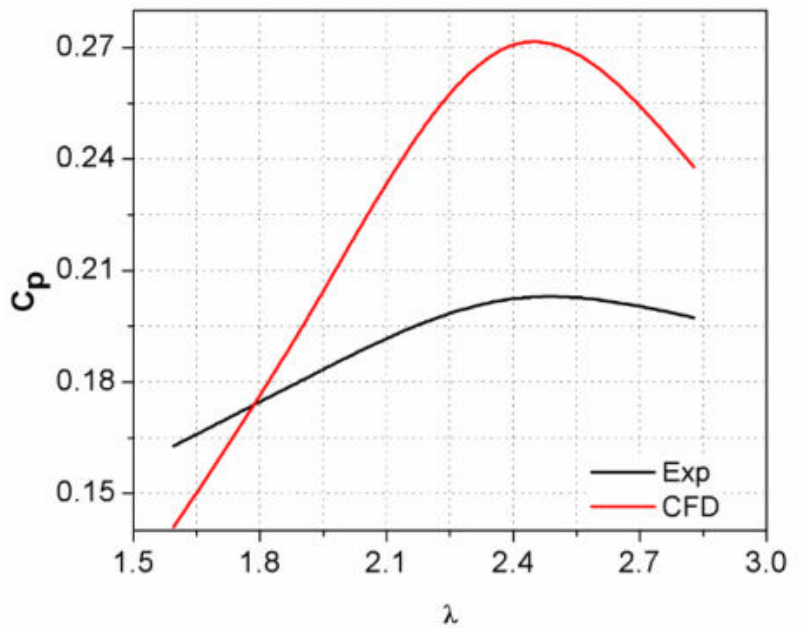

Figure 6. Validation of CFD results with established experimental results [21].

\section{Results and discussion}

A thorough numerical investigation has been carried out to determine the performance of asymmetric NACA 63415 blade VAWT with different trailing edge blade twist angle shown in Fig. 7.

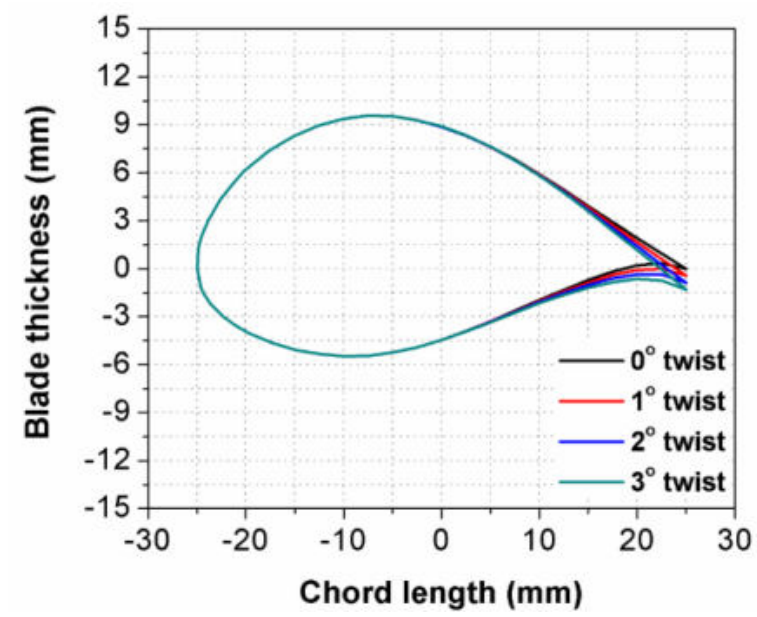

Figure 7. Airfoil twist angles used for present 2D numerical simulation.
In the present investigation $0^{\circ}-3^{\circ}$ blade twist has been considered and the thickness of the airfoil is considered to be $30 \%$ as being the optimum [21]. The variation of $C_{p}$ against different tip speed ratio (TSR) is shown in Fig. 8 for different twist angles and also validated the trend of the curve with [25]. The variations in TSR range occur due to different solidities of the turbines. Generally, turbines with symmetric airfoils show better performance in higher wind speed $(U>6.0 \mathrm{~m} / \mathrm{s})$. But, in the present paper investigation has been performed considering built environment, which has less wind speed $(U \leq 6.0 \mathrm{~m} / \mathrm{s})$ and in this situation self-starting problem of turbine is raised, which can be overcome by using asymmetric airfoils [28,29]. Also in real city condition i.e. in urban area, the average wind speed can be lower than $6.0 \mathrm{~m} / \mathrm{s}$. However, asymmetric H-Darrieus turbine can still function in suitable locations having higher wind speed like those which have accelerated shear layers, for e.g. rooftops of high rise buildings and also the developed passage that links the areas of positive and negative pressure [30]. Although, the wind speed in real city condition is less, which also depends upon its geographical location, in well planned cities there are certain locations where the magnitude of wind speed can be brought to a higher value than the average wind speed of the city. Some of such locations where it would be possible are: (a) on rooftops [31], (b) in between two buildings [32], (c) inside through building opening[33], (d) on building's skin [34]. The increased wind speeds in such locations are found to be $5.85 \mathrm{~m} / \mathrm{s}$ [35], $5.5 \mathrm{~m} / \mathrm{s}$ [36], $5.25 \mathrm{~m} / \mathrm{s}$ [37], which are close to the wind speed investigated in the present work.

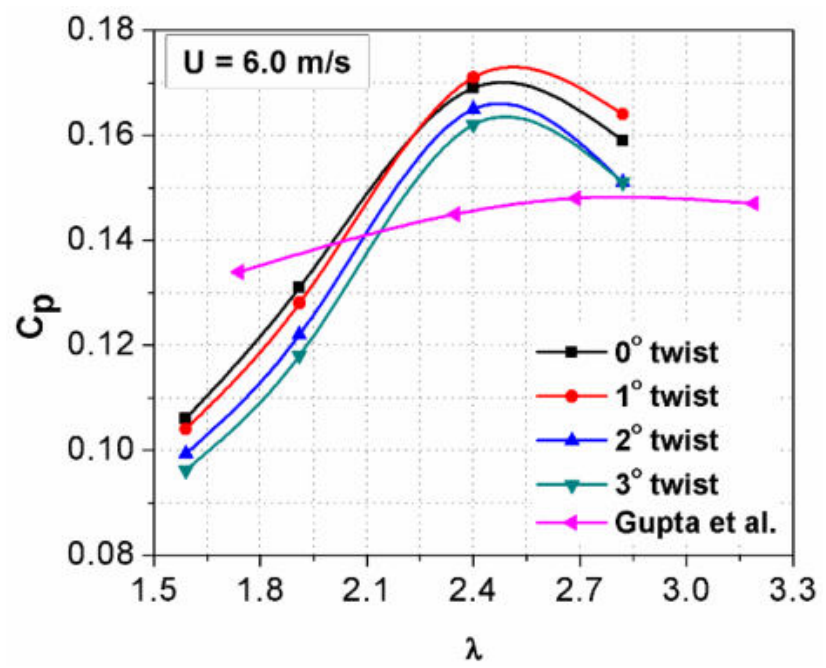

Figure 8. Variations of $C_{p}$ with TSR for different degree of blade twist turbine and also compared with existing results [27].

A minor improvement in performance in terms of maximum $\mathrm{C}_{\mathrm{p}}$ is visible at $1^{\circ}$ twist at TSR 2.4 and this improvement is more visible with further increase in TSR. Further increase in blade twist decrease $C_{p}$ of the turbine. Although the difference in $C_{p}$ is comparatively less, for a 
bigger configuration of turbine with same aspect ratio the same will proportionately have a sizable difference in performance. Gupta et al.[27] investigated the performance of H-Darrieus VAWT considering symmetrical airfoil with trailing edge blade twist. Their results are compared with present results. The power coefficient of the present turbine having asymmetric airfoil with trailing edge blade twist is found better compared to the turbine having symmetrical airfoil with trailing edge blade twist as seen in Fig. 8.

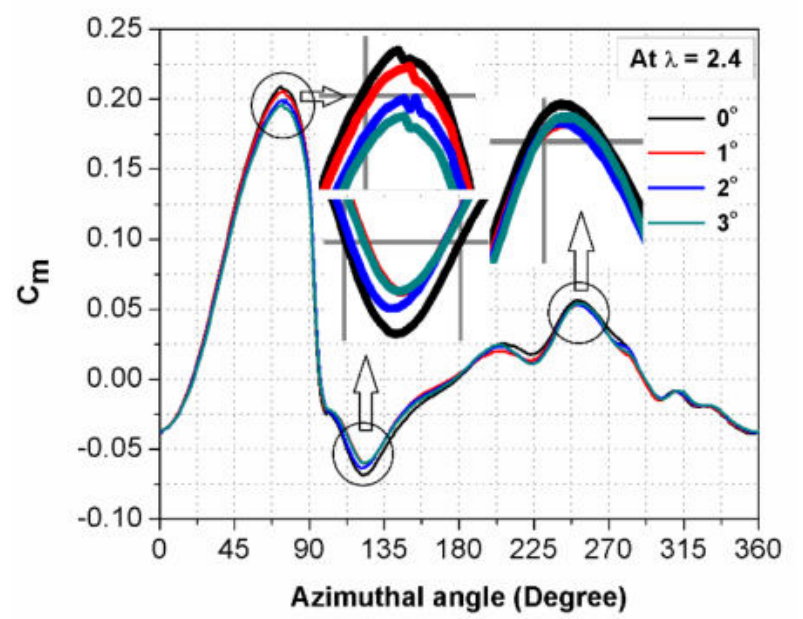

Figure 9. Variations of $C_{m}$ with $\theta$ for different degree of blade twist turbine.

The variation of $C_{m}$ with azimuthal angle $(\theta)$ for different trailing edge blade twist angle is shown in Fig. 9. A marginal increase in $C_{m}$ is visible for azimuthal angle $75^{\circ}$ at $0^{\circ}$ twist but at azimuthal position $124^{\circ}$ the value of $C_{m}$ is lower compared to $1^{\circ}$ twist turbine and the average $C_{m}$ is higher for $1^{\circ}$ twist turbine, which results in increase in $C_{p}$ for this turbine at TSR 2.4 (Fig.8). The $0^{\circ}$ blade twist has positive maximum and negative maximum $C_{m}$ at $75^{\circ}$ and $124^{\circ}$ azimuthal position shown in Fig. 9. The values of average $C_{m}$ for all turbine configuration is given in Table 3.

Table 3. Details of average moment coefficient $\left(\mathrm{Cm}_{\mathrm{m}}\right)$ for different turbine configurations.

\begin{tabular}{cc}
\hline Turbine configuration & Average $\mathrm{C}_{\mathrm{m}}$ \\
\hline No blade twist turbine $\left(0^{\circ}\right)$ & 0.023442722 \\
$1^{\circ}$ blade twist turbine & 0.02366121 \\
$2^{\circ}$ blade twist turbine & 0.022786319 \\
$3^{\circ}$ blade twist turbine & 0.022387913 \\
\hline
\end{tabular}

At $252^{\circ}$ azimuthal position there is a negligible increase in $\mathrm{C}_{\mathrm{m}}$ for $0^{\circ}$ twist turbine. Hence, at downwind position effect of blade twist is negligible at low wind speed. The results at the other two twist angles lie in between the $0^{\circ} \&$ $1^{\circ}$ blade pitch results.

\section{Conclusions}

An aerodynamic performance is carried out using 2D numerical simulation for different trailing edge blade twists $\left(1^{0}-3^{0}\right)$. Detailed insights of blade twist effect are obtained by analyzing important aerodynamic parameters at low operating wind speed $6.0 \mathrm{~m} / \mathrm{s}$. The major conclusions are summarized as below-

(a) A maximum power coefficient of 0.171 is obtained at TSR 2.4 for $1^{\circ}$ blade twist turbine and with further increase in TSR, power coefficient of $1^{\circ}$ blade twist turbine is still greater than other blade twist turbines. Thus, the asymmetric blade $\mathrm{H}$-Darrieus turbine with $1^{\circ}$ blade twist has overall higher aerodynamic performance.

(b) Although, a minor increment is achieved with $1^{\circ}$ blade twist but, further increase in blade twist drastically reduces the turbine performance.

(c) A minor difference in moment coefficient is noticed between $0^{\circ}$ and $1^{\circ}$ blade twist turbine, although the average moment coefficient is higher for $1^{\circ}$ blade twist turbine in many azimuthal ranges.

(d) The present study shows that blade twist should be very low for low wind speed application of $\mathrm{H}$ Darrieus VAWT.

\section{Acknowledgements.}

Author would like to thank and acknowledge the computational Lab facility, Department of Mechanical Engineering, NIT Silchar, India.

\section{References}

[1] Bouzaher MT, Hadid M. Numerical Investigation of a Vertical Axis Tidal Turbine with Deforming Blades. Arab J Sci Eng 2017;42:2167-78. doi:10.1007/s13369017-2511-5.

[2] Bouzaher MT, Hadid M, Semch-Eddine D. Flow control for the vertical axis wind turbine by means of flapping flexible foils. J Brazilian Soc Mech Sci Eng 2017;39:457-70. doi:10.1007/s40430-016-0618-3.

[3] Bouzaher MT, Guerira B, Hadid M. Performance analysis of a vertical axis tidal turbine with flexible blades. J Mar Sci Appl 2017;16:73-80. doi:10.1007/s11804-017-1391-0.

[4] Bouzaher MT, Drias N, Guerira B. Improvement of Energy Extraction Efficiency for Flapping Airfoils by Using Oscillating Gurney Flaps. Arab J Sci Eng 2019;44:809-19. doi:10.1007/s13369-018-3270-7.

[5] Gupta R, Biswas A. Computational fluid dynamics analysis of a twisted three-bladed H-Darrieus rotor. J Renew Sustain Energy 2010;2. doi:10.1063/1.3483487. Biswas A, Gupta R. Unsteady aerodynamics of a twist bladed H-Darrieus rotor in low Reynolds number flow. J Renew Sustain Energy 2014;6. doi:10.1063/1.4878995.

[7] Beri H, Yao Y. Numerical simulation of unsteady flow to show self-starting of vertical axis wind turbine using fluent. J Appl Sci 2011;11:962-70. 
doi:10.3923/jas.2011.962.970.

[8] Sobhani E, Ghaffari M, Maghrebi MJ. Numerical investigation of dimple effects on darrieus vertical axis wind turbine. Energy 2017;133:231-41.

doi:10.1016/j.energy.2017.05.105.

[9] Ismail MF, Vijayaraghavan K. The effects of aerofoil profile modification on a vertical axis wind turbine performance. Energy 2015;80:20-31.

doi:10.1016/j.energy.2014.11.034.

[10] Bianchini A, Balduzzi F, Di Rosa D, Ferrara G. On the use of Gurney Flaps for the aerodynamic performance augmentation of Darrieus wind turbines. Energy Convers Manag 2019;184:402-15.

doi:10.1016/j.enconman.2019.01.068.

[11] Svorcan J, Stupar S, Komarov D, Peković O, Kostić I. Aerodynamic design and analysis of a small-scale vertical axis wind turbine. J Mech Sci Technol 2013;27:2367-73. doi:10.1007/s12206-013-0621-x.

[12] Roh SC, Kang SH. Effects of a blade profile, the Reynolds number, and the solidity on the performance of a straight bladed vertical axis wind turbine. J Mech Sci Technol 2013;27:3299-307. doi:10.1007/s12206013-0852-x.

[13] Chen Y, Lian Y. Numerical investigation of vortex dynamics in an H-rotor vertical axis wind turbine. Eng Appl Comput Fluid Mech 2015;9:21-32. doi:10.1080/19942060.2015.1004790.

[14] Menter FR, Kuntz M, Langtry R. Ten Years of Industrial Experience with the SST Turbulence Model. Turbul Heat Mass Transf 4 2003;4:625-32. doi:10.4028/www.scientific.net/AMR.576.60.

[15] Menter FR, Langtry RB, Likki SR, Suzen YB, Huang PG, Völker S. A Correlation-Based Transition Model Using Local Variables-Part I: Model Formulation. J Turbomach 2006;128:413. doi:10.1115/1.2184352.

[16] Langtry RB, Menter FR, Likki SR, Suzen YB, Huang PG, Völker S. A Correlation-Based Transition Model Using Local Variables-Part II: Test Cases and Industrial Applications. J Turbomach 2006;128:423. doi:10.1115/1.2184353.

[17] Almohammadi KM, Ingham DB, Ma L, Pourkashan M. Computational fluid dynamics (CFD) mesh independency techniques for a straight blade vertical axis wind turbine. Energy 2013;58:483-93. doi:10.1016/j.energy.2013.06.012.

[18] Mohamed MH, Ali AM, Hafiz AA. CFD analysis for H-rotor Darrieus turbine as a low speed wind energy converter. Eng Sci Technol an Int J 2015;18:1-13. doi:10.1016/j.jestch.2014.08.002.

[19] Hashem I, Mohamed MH. Aerodynamic performance enhancements of H-rotor Darrieus wind turbine. Energy 2018;142:531-45. doi:10.1016/j.energy.2017.10.036.

[20] Rezaeiha A, Kalkman I, Blocken B. Effect of pitch angle on power performance and aerodynamics of a vertical axis wind turbine. Appl Energy 2017;197:13250. doi:10.1016/j.apenergy.2017.03.128.

[21] Mazarbhuiya HMSM, Biswas A, Sharma KK. Performance investigations of modified asymmetric blade H-Darrieus VAWT rotors. J Renew Sustain Energy 2018;033302. doi:10.1063/1.5026857.

[22] Raciti Castelli M, Englaro A, Benini E. The Darrieus wind turbine: Proposal for a new performance prediction model based on CFD. Energy 2011;36:491934. doi:10.1016/j.energy.2011.05.036.

[23] Wang Y, Shen S, Li G, Huang D, Zheng Z. Investigation on aerodynamic performance of vertical axis wind turbine with different series airfoil shapes. Renew Energy 2018;126:801-18. doi:10.1016/j.renene.2018.02.095.

[24] Gosselin R, Dumas G, Boudreau M. Parametric study of H-Darrieus vertical-axis turbines using CFD simulations. J Renew Sustain Energy 2016;8. doi:10.1063/1.4963240.

[25] Mazarbhuiya HMSM, Biswas A, Sharma KK. Blade thickness effect on the aerodynamic performance of an asymmetric NACA six series blade vertical axis wind turbine in low wind speed. Int J Green Energy 2020;17:171-9. doi:10.1080/15435075.2020.1712214.

[26] Howell R, Qin N, Edwards J, Durrani N. Wind tunnel and numerical study of a small vertical axis wind turbine. Renew Energy 2010;35:412-22.

doi:10.1016/j.renene.2009.07.025.

[27] Gupta R, Biswas A. Performance measurement of a twisted three-bladed airfoil-shaped H-rotor 2010;1:279-300.

[28] Singh MA, Biswas A, Misra RD. Investigation of selfstarting and high rotor solidity on the performance of a three S1210 blade H-type Darrieus rotor. Renew Energy 2015;76:381-7. doi:10.1016/j.renene.2014.11.027.

[29] Batista NC, Melício R, Mendes VMF, Calderón M, Ramiro A. On a self-start Darrieus wind turbine: Blade design and field tests. Renew Sustain Energy Rev 2015;52:508-22. doi:10.1016/j.rser.2015.07.147.

[30] Ayhan D, Sağlam A. A technical review of buildingmounted wind power systems and a sample simulation model. Renew Sustain Energy Rev 2012;16:1040-9. doi:10.1016/j.rser.2011.09.028.

[31] Abohela I, Hamza N, Dudek S. Effect of roof shape, wind direction, building height and urban configuration on the energy yield and positioning of roof mounted wind turbines. Renew Energy 2013;50:1106-18. doi:10.1016/j.renene.2012.08.068.

[32] Blocken B, Stathopoulos T, Carmeliet J. Wind Environmental Conditions in Passages between Two Long Narrow Perpendicular Buildings. J Aerosp Eng 2008;21:280-7. doi:10.1061/(ASCE)08931321(2008)21.

[33] Li QS, Shu ZR, Chen FB. Performance assessment of tall building-integrated wind turbines for power generation. Appl Energy 2016;165:777-88. doi:10.1016/j.apenergy.2015.12.114.

[34] Park J, Jung HJ, Lee SW, Park J. A new buildingintegrated wind turbine system utilizing the building. Energies 2015;8:11846-70. doi:10.3390/en81011846.

[35] Arteaga-López E, Ángeles-Camacho C, BañuelosRuedas F. Advanced methodology for feasibility studies on building-mounted wind turbines installation in urban environment: Applying CFD analysis. Energy 2019;167:181-8. doi:10.1016/j.energy.2018.10.191.

[36] Dilimulati A, Stathopoulos T, Paraschivoiu M. Wind turbine designs for urban applications: A case study of shrouded diffuser casing for turbines. J Wind Eng Ind Aerodyn 2018;175:179-92. doi:10.1016/j.jweia.2018.01.003.

[37] Sotoudeh F, Kamali R, Mousavi SM. Field tests and numerical modeling of INVELOX wind turbine application in low wind speed region. Energy 2019;181:745-59. doi:10.1016/j.energy.2019.05.186. 